\title{
Shaping Sustainable Service Ecosystems: An Analysis of Some Possible Enhancing Factors
}

\author{
FRANCESCA IANDOLO \\ francesca.iandolo@uniroma1.it \\ Sapienza University of Rome
}

\author{
SILVIA COSIMATO \\ silvia.cosimato@unina.it \\ University of Naples Federico II
}

\begin{abstract}
Over the last years, sustainability and sustainable development have gained momentum also in-service research. Thus, this works is aimed at investigating the evolutionary path that links the Viable Systems Approach (VSA), service systems and service ecosystems perspectives to the most recent challenges of sustainability. Therefore, the analysis has been focused on startups' ability to survive contributing to the shaping of a service ecosystem, which long-term viability can be ensured merging efficiency, effectiveness and sustainability targets. In this direction, the way networked interactions, occurring between a number of different actors (e.g., start-ups, customers, incubators, venture capitalists, other corporations, banks, education and financial institutions, governments) and facilitated by the most recent technologies, can shape a sustainable service ecosystem able to ensure viability to the actors who populate it has been investigated. To this end, an empirical analysis has been conducted to better define the main processes that can shape a start-ups' sustainable service ecosystem. This work represents one of the first attempts to investigate start-ups' surviving according to a service ecosystem perspective. An agenda for further research has been defined in order to further advance the analysis.
\end{abstract}

\section{Introduction}

In recent times, service research has called attention to the number of challenges that sustainability poses, highlighting the need for reducing the negative influence that service can have on economic, social, and environmental activities (Waage, 2007). In this direction, a sustainable approach to service calls for a more holistic perspective able to go beyond the traditional individuals, dyads or groups analysis to approach service systems, service networks, and service ecosystems (Barile et al., 2016). This has led to the spread of a system approach to value creation (Meynhardt et al., 2016), which the conceptualisation of service ecosystems, intended as complex networks of self-organised, but interdependent actors/entities, linked together by service-for-service interactions (Akaka et al., 2012; Lusch and Vargo, 2014; Vargo and Lusch, 2017). These interactions are dynamic in nature, being based 
on actors/entities ongoing resources' sharing, combining and recombining, which a mutual institutional logic inspires and directs (Vargo and Akaka, 2012). It follows that service ecosystems and the actors that populate their multiple levels (micro, meso and macro) tend to co-evolve in a non-linear way, always adjusting the ecosystem structure to make it viable in the long-run (Vargo et al., 2008). Drawing on the more extensive literature on ecosystem, this viability lies also upon the ongoing resource integration for value co-creation, which led to create in a collaborative and dynamic way or to co-create knowledge always new. This conceptualisation lies upon the previous literature on knowledge ecosystems (Nonaka and Takaeuci, 1995; Maracine and Scarlat, 2009; Valkokari, 2015), which more recently also inspired the SD Logic in conceptualising the afore-mentioned service ecosystems (Vargo and Lusch, 2011). Therefore, assuming a more holistic perspective on phenomena, the ecosystem view let to better understand the essential conditions of sustainable development, based on the harmonisation of the socio-economic and environmental context and on the dynamic balancing of intertwined multi-actor interactions (Barile et al., 2016). Taking a wider perspective, several potential connections between sustainability and service research can be underlined, merging the foundational concepts of systems thinking (Bogdanov, 1913; Von Bertalanffy, 1969), the VSA (Barile, 2000, 2009; Golinelli, 2000, 2010) with the SD Logic (Vargo and Lusch, 2008, 2016, 2017) and the SS (Spohrer et al., 2007; Maglio and Spohrer, 2008). It follows that the analysis has been conducted according to the main conceptualisations of the Viable System Approach (VSA) (Barile, 2000, 2009; Golinelli, 2001; 2010), inspired by Stafford Beer's $(1979,1984)$ Viable System Model, which represents a suitable interpretative framework for better understanding the importance of sustainability for systems viability (Barile et al., 2016).

This study is theoretical in nature, being intended to define and discuss the interactions that shape a sustainable start-ups service ecosystem, based on networked interactions that bond actors to other entities/systems - such as customers, suppliers, incubators, venture capitalists, institutions and government - with the aim of overcoming both inner and contextual constrains (Bala Subrahmanya, 2017).

The remainder of the paper is organised as follows. After a brief investigation of the theoretical background of this analysis, presented in Section 2 (service-for-service relationships; nested and networked interactions; value, efficiency, effectiveness, and sustainability perspectives), Section 3 approaches start-ups according to the ecosystem perspective, describing the interactions occurring between different actors at each level (micro, meso and macro). Section 4 has been dedicated to the theoretical presentation and discussion of the main characteristic of sustainable start-ups service ecosystem at each of three levels. Close implications and final remarks.

\section{Theoretical background}

\subsection{The evolutionary path from systems towards ecosystems: a sustainable orientation}

The growing attention that society, policy and science have paid to sustainability led service research to progressively approach this topic (Saviano et al., 2017). In fact, the current socioeconomic scenarios, characterised by complex issues such as the dematerialisation, socialisation, networking, servuction and similar, paved the way for analysing the single elements of businesses structures as well as their systems' dynamics (Spender, 1996), inspiring 
the VSA double approach to phenomena. This approach analyses both the single elements and the relations that bind them together shaping a 'structure' and focusing on the interactions that characterise the functioning of a system in its context (Barile et al., 2012). In the aforementioned context, systems aim to stay viable and survive in the long-run (Beer, 1985; Golinelli, 2010), adapting themselves to environmental changes and adjusting the role they perform in each context. To achieve this goal, systems have to change the way they interact with others (e.g., suppliers, customers or other stakeholders; Barile et al., 2016). In this sense, the VSA based service interactions (or service-for-service exchange) on resource (mainly information) sharing, essential for co-creating value. Therefore, service-for-service relationships (Vargo and Lusch, 2008) should be based on 'consonance', or on the closeness between the different entities that populate a system (Barile, 2009; Barile et al., 2012). Consonance can also evolve in 'resonance', a spread harmony due to the reciprocal understanding and value alignment, which drives the afore-mentioned entities towards a common goal (Barile, 2009; Barile and Polese, 2011; Barile et al., 2013). It follows that multiple interactions occurring between multiple entities can shape those network configurations on which service systems', intended as "value-co-creation configurations of people, technology, and value propositions connecting internal and external service systems and shared information (e.g., language, laws, measures and methods)" (Maglio and Spohrer, 2008: 18), are built. Thus, those network configurations bond together entities or actors with different aims, interests and values, but with a shared goal (Barile et al., 2016).

Focusing on the nested and networked interactions occurring between the entities/actors that populate service systems, SD Logic made the scope of service logic wider (Barile et al., 2016), introducing in its core narrative the conceptualisation of service ecosystems (Vargo and Lusch, 2008, 2017; Vargo and Akaka, 2012). Thus, service ecosystems have been defined as "relatively self-contained, self-adjusting system(s) of resource-integrating actors connected by shared institutional logics and mutual value creation through service exchange" (Vargo and Lusch, 2011: 161), which core elements are actors' engagement and the ongoing resource integration for value co-creation (Storbacka et al., 2016). Focusing on value, it worth noting that it is the same time an individual and a collective phenomenon, which emergence should be investigated at each of the three ecosystem levels, micro-, meso- and macro-level (Chandler and Vargo, 2011). This implies the need for going beyond a network perspective (static) to underline the inner dynamics of system behaviours spanning across the afore-mentioned levels (Vargo and Lush, 2014; Haase and Pick, 2015). Thus, assuming a systems perspective, value is not created in isolation, but rather it "emerges from micro-macro links in service ecosystems" (Meynhardt et al., 2016: 2981). This implies that value co-creation occurs when entities/actors are engaged with a mutual goal through shared institutions (humanly devised schemas, norms and regulations that enable and constrain the behaviour of social actors) and institutional arrangements (sets of interrelated institutions) (Lusch et al., 2016; Vargo and Lusch, 2017). In other words, value is co-created when actors' interactions are based on a structural consonance that led to values' alignment essential for achieving common goals (Barile et al., 2014).

The wider perspective of ecosystem approach, exploiting actor engagement in resource integration for an ongoing value co-creation (Vargo and Lusch, 2016), can boost those socioeconomic changes essential for sustainable development (Pels et al., 2014; Saviano et al., 2017). In this sense, Spohrer and Kwan (2009) considered sustainability as rising from balanced interactions between environmental, social and economic systems. This implies the double 
ability in preventing or minimising those systems' interactions that can co-destroy value and in optimising value creation for others (Van Riel et al., 2019). In a similar vein, Reynoso (2009) maintained that (eco)systems' long-lasting viability should be rooted on "balanced integration of economic, social and environmental values" (Reynoso, 2009: 475), opening to a shifting perspective that approaches actors as real suppliers of sustainability (Wolfson et al., 2011), underlining the importance of engagement with a common value creation network (or service ecosystem). More recently, Polese et al. (2017) maintained that service ecosystems can be considered sustainable just when "actors/systems interact sharing the final purpose of the ecosystem, following sustainable principles, reducing their own expectations and generating benefits primarily for the whole ecosystem" (Polese et al., 2017: 788).

\subsection{The role of ICTs in ensuring sustainability for service ecosystems / Information and communication technologies for service ecosystem sustainability}

Over the last decades, Information and Communication Technologies (ICT) have developed rapidly, becoming even more pervasive and ubiquitous. The disruptive potential of the most recent technologies has boosted the interactions among ecosystems' actors offering a more efficient and effective resource sharing (Lusch and Nambisan, 2015; Caputo and Walletzký, 2017). Thus, resource exchange is broadly considered the sine qua non for value co-creation (Prahalad and Ramaswamy, 2004; Ramaswamy and Gouillart, 2010), which technologies facilitate offering the right source of resources (information, capabilities, skills, etc.) (Hsu and Spohrer, 2009).

More recently, Service-Dominant (SD) Logic considered technologies able to enhance the density of the resources exchanged at different ecosystem levels (micro, meso and macro) (Michel et al., 2008). In this sense, acting as interactions enabler, technologies can help actors in mixing and matching "a trinity of resources: competences, relationships, and information" (Lusch and Nambisan, 2015: 164), changing the way digital and physical ecosystem components are combined and recombined (Breidbach and Maglio, 2016). Moreover, due to their high interface potential ICTs offer more engagement opportunities, a higher degree of resource integration and, in so doing, a venue for more viable systems solutions (Lusch and Nambisan, 2015; Göbel and Cronholm, 2017). More in details, these technologies facilitate those actors' interactions that contribute to the dynamic adjustment of a service ecosystem for achieving consonance with its context and, thus, for preserving its stability, viability and sustainability over the time (Barile and Polese, 2010: 30). Even though the literature has investigated the influence that technologies can have on the efficiency of ecosystem processes and the effectiveness of their outcomes, further research is still needed for better understand their potential in ensuring long-term viability or sustainability (Barile and Saviano, 2018). In fact, according to Saviano et al. $(2010,2017)$ (eco)systems' viability lies upon the ability to harmonise the internal processes efficiency, results' effectiveness for the whole context (or each ecosystem level) and the sustainability for the wider environment (e.g., the service ecosystem itself). In this direction, technologies - acting as interactions' enabler - can enhance those ongoing processes of value co-creation that contribute to ecosystems' long-term viability, balancing efficiency (or doing things in the right way), effectiveness (or the right things that must be done) and sustainability (or the effort towards the establishment of the right relationships with other systems) (Sphorer et al., 2007). 


\subsection{ICTs role in shaping a start-ups ecosystem}

The European Startup Monitor (ESM) (Kollmann et al., 2016) defined start-ups as "companies under the age of ten and have high aspirations in terms of employee growth and sales" (Kollmann et al., 2016: 55). These companies have been also considered "human institution designed to deliver a new product or service under conditions of extreme uncertainty" (Ries, 2011: 17), which development is constrained by the lack of tangible and intangible resources (Wymer and Regan, 2005). To counteract this situation, start-ups should establish collaborative relationships especially with external partners (Teece, 2010; Kask and Linton, 2013), creating a relational network able to boost resource sharing essential for nourishing their viability. This implies that start-ups "are not individual companies, they live in an ecosystem that includes other start-ups, universities, incubators, investors, among other elements" (Nougera et al., 2016: 51). In this sense, incubators and/or accelerators as well as local policy agencies act as coordinating entities, which boost actors' interactions through shared institutions able to inspire and direct towards shared goals (Alvarez et al., 2018). This implies that the long-run viability of start-ups service ecosystem mainly depends on actors' engagement in resource sharing: a process driven by specific institutions and institutional arrangement and enhanced by digital technologies (Lusch and Nambisan, 2015; Vargo and Lusch, 2017). In this sense, Orlikowski's (1992) structuration model of technology let better understand the role that technologies (influenced and directed by institutions) can have on value co-creation process (Akaka and Vargo, 2012) in terms of resource (mainly knowledge) sharing.

Service ecosystem perspective approached technologies as dynamic resources (Akaka and Vargo, 2014) or as a useful knowledge (Mokyr, 2004) that can contribute to co-create value, enabling resource sharing within and across service (eco)systems levels (Maglio and Spohrer, 2008; Chandler and Vargo, 2011). In this sense, digital technologies can support the shaping and the sustainability of a start-up ecosystem, boosting its actors' evolution and adaptiveness to the changing and unpredictable conditions of a complex and hyper-competitive environment (Palumbo et al., 2017). Follows a brief description of the main actors' interactions that - at different levels - contribute to shaping a sustainable start-ups service ecosystem.

\section{Shaping the micro-, meso- and macro-level of a sustainable start-up service ecosystem}

Drawing on the previous consideration, start-ups service ecosystems are built upon a system of resource-integrating actors, such as service organisations, clients, venture capitalists, incubators, spin-offs, banks, other corporations, universities, public institutions and government (Spender et al., 2017). These actors - connected by shared institutions (regulations, laws, policies, etc.) - share their resources to co-create mutual value for adding sustainability to the ecosystem they belong. In this sense, technologies, acting as interactions' enabler, facilitate actors' access to resources (mainly information) (Palumbo et al., 2017) making them able to create new and higher-order ones (knowledge). In other words, technologies provide those essential rules or institutions - or humanly devised schemas, norms and regulations (Koskela-Huotari and Vargo, 2016; Vargo et al., 2017) - that hold together the ecosystem, boosting Actor-to-Actor (A2A) interactions that, according to a circular logic, nourish process efficiency, output effectiveness and, then, ecosystem sustainability. 


\subsection{The micro-level interactions}

At the micro-level of an ecosystem, interactions are dyadic in nature, occurring between the focal companies (start-ups), customers, and other service providers (e.g., suppliers). These interactions are based on service-for-service exchanges, occurring in a direct and reciprocal way between dyads of actors (Beirao et al., 2016). Dyadic interactions are built upon the exchange, the combination and the recombination of resources (Vargo et al., 2008; Chandler and Vargo, 2011; Vargo and Lusch, 2011), shaping the context in which start-ups together with customers and other service providers are engaged in value co-creation process (Storbacka et al., 2016). Thus, the afore-mentioned context let to understand the reasons micro-level actors are engaged in resource integration for creating new and higher-order ones (Palumbo et al., 2017).

At this level, also thanks to the enhancing role of technologies, customers are even more involved in resource exchange together with other service providers (e.g., suppliers) pointing to create new and sometimes innovative technical, market, managerial and financial knowledge (Hardyman et al., 2015).

What mainly characterises the micro-level of a start-ups service ecosystem is actors' engagement, which boosts those dyadic interactions (Beirao and Patricio, 2016) occurring between start-ups and other service providers (e.g., suppliers, partners, etc.) as well as startups and customers. At this level, the afore-mentioned individual actors tend to be engagement in collaborative and cooperative interaction, according to which they share, combine and recombine their personal resources (mainly information, skills and knowledge) to produce new ones (e.g., new products or services, new processes, new markets, new business models, etc.). Moreover, policy, legal and financial arrangements (institutional logic) shape the context in which starting from the micro-level actors are engaged in different resource integration patterns.

\subsection{The sustainable start-up service ecosystems: the meso level interactions}

At the meso-level of a start-up ecosystem, situational and transformational mechanisms occur paving the way for the understanding of emerging dynamic changes (Dopfer et al., 2004; Jepperson and Meyer, 2011). At this level are usually situated the so-called middle-range organisations or coordinating entities, which participate to those transformational mechanisms that bond micro-level process of actors' engagement to the process of value cocreation occurring at the macro-level (Storbacka et al., 2016). As stated, other organisations populate the meso-level, such as incubators, venture capitalists, banks and other corporation, which directly and indirectly interact to co-create value. It follows that resource sharing at the core of value co-creation is based on information flow and on communication between the actors (organisations) placed at this level and those (start-ups, clients, service providers) placed at the micro-level. Thus, the interactions occurring at the meso level shape the right context (Spender et al., 2017) for value co-creation, facilitating the access to and the sharing of resources (e.g., knowledge, information, financing, etc.) and therefore start-ups growth. In this sense, acting as interactions enablers, technologies boost that knowledge sharing and transfer essential for triggering products, services or processes innovation, performances enhancement, and growth in investment intensity in R\&D (Soetanto and Van Geenhuizen, 2015). 
Focusing on financial organisations such as banks and/or venture capitalists, their intra- and inter-level collaborative interactions are often aimed at offering financial support to start-ups, bridging the gap that public programmes usually create. In a similar vein, incubators participates to start-ups lifecycle from "the pre-seed stage until the commercialization stage" (Spender et al., 2017: 20), stimulating at each of these stage innovation, acting for example as technology incubator (Kaufmann and Schwartz, 2008), industrial incubator (Rasmussen and Clausen, 2015), and university incubator (Rubin et al., 2015). Moreover, start-ups viability can be also nourished interacting with other corporations, especially when bigger in dimension, for example, developing outside-in and platform start-up programmes (Weiblen and Chesbrough, 2015) intended to create long-lasting partnerships (Simon, 2018) with the other middle-range organisations that populate the meso level. Therefore, venture capitalists, incubators, spin-off and other corporations actively contribute to boosting the (co)creation of new knowledge to share inside and outside this level (Ferrary and Granovetter, 2009; Albats et al., 2018).

In sum, these meso level actors contribute to long-lasting viability of the ecosystem selecting, mentoring and championing start-ups projects (Ferrary and Granovetter, 2009; Strömsten and Waluszewski, 2012), which can develop a network of interactions in which the meso level organisations perform as resource interfaces to micro-level actors. In this sense, for example, spin-offs represent the right interface for enhancing start-ups interaction and collaboration with universities (Albats et al., 2018), in order to "reduce the time and effort allocated for exploring external resources" (Wareham et al., 2014: 35).

\subsection{The sustainable start-up service ecosystems: the macro level interactions}

Macro-level actors are national and international government, educational and legal institutions, which contribute to shaping service ecosystems, driving the behaviour of both micro and meso level actors. This is possible setting the institutional and policy conditions for the implementation and the proper functioning of the ecosystem (Beirao et al., 2017). This implies the definition of those shared norms and rules (institutions), which enable or constrain the meso and micro-level interactions (Lusch and Vargo, 2014). In this sense, the role of government in the emergence of new institutions and institutional arrangements is fundamental for the sustainability of the whole ecosystem (Beirao et al., 2017). Thus, macrolevel actors contribute to improving processes' efficiency, system effectiveness and, therefore, the long-run surviving or sustainability of the ecosystem itself. More in details, government and institutional organisations set the right conditions for start-ups growth and viability, supporting knowledge-intensive, research-based and high-technology-based interactions (Carayannis et al., 2018) thanks to the establishment of a dense interaction network able to boost organisations evolution according to the ever-changing external environment (Lee and Shin, 2018). However, further investigations are needed for a better understanding of how and which government programmes and policies might be appropriate for supporting and promoting start-ups' sustainability growth.

Moving the focus on financial institutions, they are used to set the rules, regulations and laws that drive start-ups access to financial resources as well as their interactions with meso level financial actors (e.g., venture capitalists, banks, spin-offs, and other corporations). Finally, education institutions act as interface between knowledge producers and consumers (e.g., 
start-ups), supporting them in defining opportunities, mobilise resources and create an organisation (McDermott et al., 2018).

Figure 3.3.1 depicts the multi-actor interactions that shape a sustainable start-up service ecosystem.

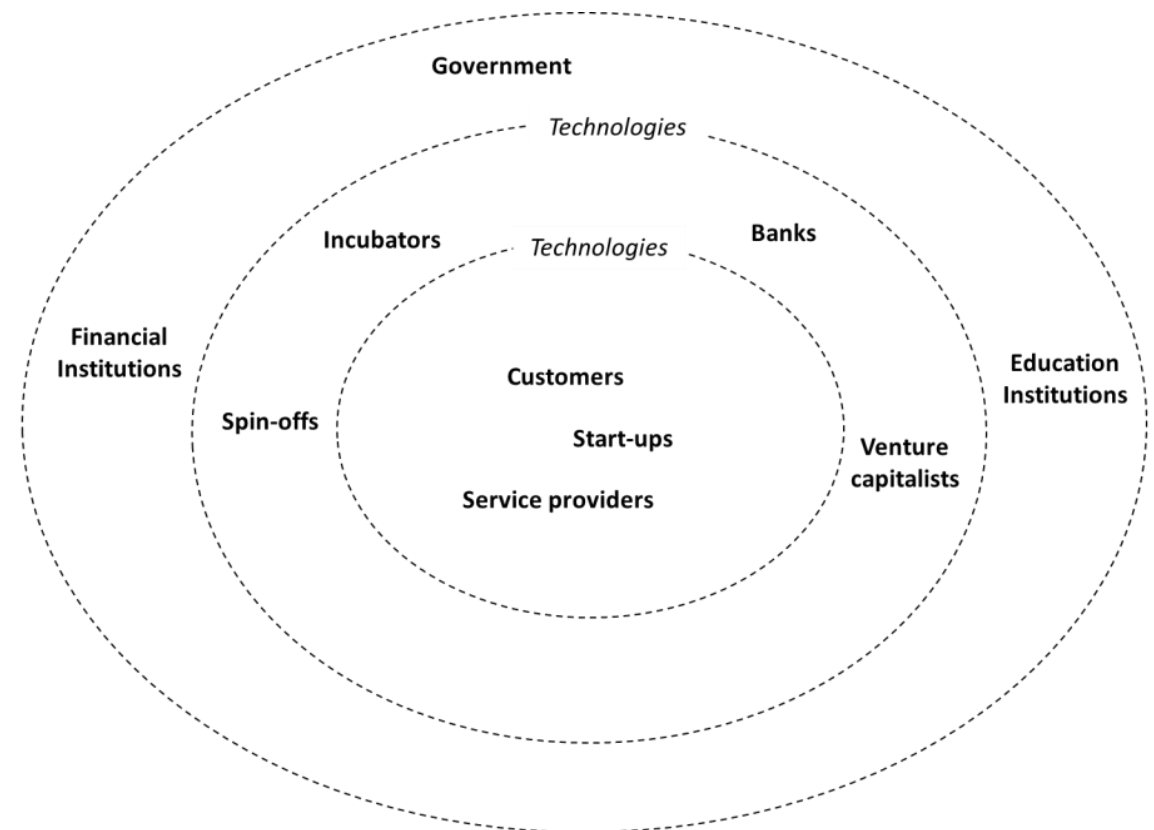

Figure 3.3.1. Sustainable Start-ups service ecosystem (source: authors' elaboration).

\section{Implications and final remarks}

This study has been intended to better understand the interactions that shape and make sustainable a start-ups service ecosystem. In this direction, multi-actors inter and intra levels interactions have been described and argued, defining a system approach to start-ups development, which is supported by the active contribution of customers, service providers, incubators, venture capitalists, institutions and other relevant stakeholders (Ries, 2011).

Assuming a service ecosystem perspective, it has been possible to define and support multiple and more effective sustainable co-creating interactions (Pels et al., 2014) able to offer mutual and inclusive outcomes. To this end, it is fundamental the promotion of an open and easy access to resources, enabled by technologies, that can enhance at the micro level the engagement of actors in resource sharing, combination and recombination facilitated by the collaborative relationships established with the meso level organisations and driven by the institutions created at the macro level. In this direction, technology enhance those interchangeable multi-actor interactions, which - according to the Actor-to-Actor (A2A) logic - makes all socio-economic actors able to participate in value creation in a fundamentally similar way (Wieland et al., 2016). Moreover, the A2A logic led to better understand the importance and the criticality of actors' willingness to share and combine their personal resources for generating new knowledge, characterised by a growing density due to the good integration within the ecosystem itself (Chen and Liang, 2011; Nonaka and Toyama, 2015). In this sense, technologies facilitating multi-actor interactions and the subsequent resource 
sharing (mainly information) can lead to creating new ones, especially new and more dense knowledge able to nourish the long-term viability of a service ecosystem. Thus, the ecosystem perspective can boost knowledge exchanged opportunities and 'seed' 'positive behavioural antecedents'. This implies that technologies can enhance start-ups viability, boosting actors' engagement in the process of mutual resource sharing, with a number of different actors (e.g., customers, incubators, education institutions, governments, etc.). Therefore, the classification rising from the theoretical analysis might support start-ups in achieving a more effective resource management, also through the establishment of collaborative co-creative partnership with other actors (e.g., the middle range organisations placed at the meso level), pointing to ensure to all involved parties a long-lasting viability (Barile et al., 2016). Even if the findings showed the importance of institutions for governance and viability purpose (Vargo and Lusch, 2017), further empirical research is still needed, in order to address the effective contribution of each actor to ecosystem efficiency, effectiveness and sustainability.

\section{Keywords}

service systems; service ecosystems; viable systems approach (VSA); service-dominant (SD) logic; sustainability; start-ups

\section{References}

Akaka, M.A., and Vargo, S.L. (2014), “Technology as an Operant Resource in Service (Eco) Systems", Information Systems and e-Business Management, 12 (3): 367-384.

Akaka, M., Vargo, S.L., and Lusch, R.F. (2012), "An Exploration of Networks in Value Cocreation: A Service-Ecosystems View", in S.L. Vargo and R.F. Lusch (eds), Toward a Better Understanding of the Role of Value in Markets and Marketing, Special Issue of Review of Marketing Research, 9: 13-50.

Albats, E., Fiegenbaum, I., and Cunningham, J.A. (2018), “A Micro Level Study of University Industry Collaborative Lifecycle Key Performance Indicators", The Journal of Technology Transfer, 43 (2): 389-431.

Alvarez, S., Carayannis, E.G., Dagnino, G.B., and Faraci, R. (2018), "Introduction: Entrepreneurial Ecosystems and the Diffusion of Startups", in E.G. Carayannis, G.B. Dagnino, S. Alvarez and R. Faraci (eds), Entrepreneurial Ecosystems and the Diffusion of Startups, 1-10,London: Edward Elgar Publishing.

Andersson, E., McPhearson, T., Kremer, P., Gomez-Baggethun, E., Haase, D., Tuvendal, M., and Wurster, D. (2015), "Scale and Context Dependence of Ecosystem Service Providing Units", Ecosystem Services, 12: 157-164.

Bala Subrahmanya, M.H. (2017), “How Did Bangalore Emerge as a Global Hub of Tech StartUps in India? Entrepreneurial Ecosystem: Evolution, Structure and Role", Journal of Developmental Entrepreneurship, 22 (1): 1-22.

Barile, S. (2000), Contributi sul Pensiero Sistemico in Economia d'Impresa, Salerno: Arnia.

Barile, S. (2009), Management Sistemico Vitale (Vol. 1), Turin: Giappichelli. 
Barile, S., and Polese, F. (2011), "An Introduction to the Viable Systems Approach and its Contribution to Marketing", in S. Barile (ed.), Contributions to Theoretical and Practical Advances in Management: A Viable System Approach, 1-39, Rome: Aracne.

Barile, S., and Polese, F. (2010), "Smart Service Systems and Viable Service Systems: Applying Systems Theory to Service Science", Service Science, 2 (1-2): 21-40.

Barile, S., and Saviano, M. (2018), “Complexity and Sustainability in Management: Insights from a Systems Perspective", in S. Barile, M. Pellicano and F. Polese (eds), Social Dynamics in a Systems Perspective, 39-63, Cham (Switzerland): Springer.

Barile, S., Carrubbo, L., Iandolo, F., and Caputo, F. (2013), "From 'EGO' to 'ECO' in B2B Relationships", jbm - Journal of Business Market Management, 6 (4): 228-253.

Barile, S., Lusch, R., Reynoso, J., Saviano, M., and Spohrer, J. (2016), “Systems, Networks, and Ecosystems in Service Research", Journal of Service Management, 27 (4): 652-674.

Barile, S., Saviano, M., Polese, F., and Di Nauta, P. (2012), “Il Rapporto Impresa-Territorio tra Efficienza Locale, Efficacia di Contesto e Sostenibilità Ambientale", in S. Barile, M. Saviano, F. Polese and P. Di Nauta (eds), Il Rapporto Impresa-Territorio tra Efficienza Locale, Efficacia di Contesto e Sostenibilità Ambientale, 387-402, Lecce: Università del Salento.

Beer, S. (1979), The Heart of Enterprise (Vol. 2), London: John Wiley \& Sons Inc.

Beer, S. (1984), “The Viable System Model: Its Provenance, Development, Methodology and Pathology", Journal of the Operational Research Society, 35 (1): 7-25.

Beer, S. (1985), Diagnosing the System for Organizations, London: John Wiley \& Sons Inc.

Beirão da Veiga, L., Brezzi, F., Marini, L.D., and Russo, A. (2016), “Virtual Element Method for General Second-Order Elliptic Problems on Polygonal Meshes", Mathematical Models and Methods in Applied Sciences, 26 (4): 729-750.

Beirão, G., Patrício, L., and Fisk, R.P. (2017), "Value Cocreation in Service Ecosystems: Investigating Health Care at the Micro, Meso, and Macro Levels", Journal of Service Management, 28 (2): 227-249.

Bogdanov, A.A. (1913), Vseobshchaia organizatsionnaia nauka: Tektologiia [Theory of Organization, or Tektology], Saint Petersburg: Izdanie M.I. Semenova.

Breidbach, C.F., and Maglio, P.P. (2016), “Technology-Enabled Value Co-Creation: An Empirical Analysis of Actors, Resources, and Practices", Industrial Marketing Management, 56: 73-85.

Caputo, F., and Walletzký, L. (2017), “Investigating the Users' Approach to ICT Platforms in the City Management", Systems, 5 (1): 1-15.

Carayannis, E.G., Dagnino, G.B., Alvarez, S., and Faraci, R. (eds) (2018), Entrepreneurial Ecosystems and the Diffusion of Startups, New York (NY): Edward Elgar Publishing.

Chandler, J.D., and Vargo, S.L. (2011), “Contextualization and Value-In-Context: How Context Frames Exchange", Marketing Theory, 11 (1): 35-49.

Chen, D.N., and Liang, T.P. (2011), "Knowledge Evolution Strategies and Organizational Performance: A Strategic Fit Analysis", Electronic Commerce Research and Applications, 10 (1): 75-84.

Dopfer, K., Foster, J., and Potts, J. (2004), “Micro-Meso-Macro", Journal of Evolutionary Economics, 14 (3): 263-279. 
Enquist, B., Petros Sebhatu, S., and Johnson, M. (2015), "Transcendence for Business Logics in Value Networks for Sustainable Service Business", Journal of Service Theory and Practice, 25 (2): 181-197.

Ferrary, M., and Granovetter, M. (2009), “The Role of Venture Capital Firms in Silicon Valley's Complex Innovation Network", Economy and Society, 38 (2): 326-359.

Göbel, H., and Cronholm, S. (2017), "Guidelines for Service-Dominant Logic: Empirical Experiences from IT Service Management", in E. Gummesson, C. Mele and F. Polese (eds), Service Dominant Logic, Network and Systems Theory and Service Science: Integrating Three Perspectives for a New Service Agenda, 6-9, Proceedings of the $5^{\text {th }}$ Naples Forum on Service.

Golinelli, G.M. (2000), L'Approccio Sistemico al Governo dell'Impresa (Vol. 1), Padova: CEDAM.

Golinelli, G.M. (2010), Viable Systems Approach (VSA): Governing Business Dynamics, Padova: CEDAM.

Haase, M., and Pick, D. (2015), “Value Creation in Sharing Networks: Towards a Typology of Sharing Networks", in M. Bruhn and K. Hadwich (eds), Interaktive Wertschöpfung durch Dienstleistungen: Strategische Ausrichtung von Kundeninteraktionen, Geschäftsmodellen und sozialen Netzwerken. Forum Dienstleistungsmanagement, 439-468, Wiesbaden: Springer Gabler.

Hardyman, W., Daunt, K.L., and Kitchener, M. (2015), “Value Co-Creation through Patient Engagement in Health Care: A Micro-Level Approach and Research Agenda", Public Management Review, 17 (1): 90-107.

Hsu, C., and Spohrer, J.C. (2009), “Improving Service Quality and Productivity: Exploring the Digital Connections Scaling Model", International Journal of Services Technology and Management, 11 (3): 272-292.

Jepperson, R., and Meyer, J.W. (2011), "Multiple Levels of Analysis and the Limitations of Methodological Individualisms", Sociological Theory, 29 (1): 54-73.

Kask, J., and Linton, G. (2013), “Business Mating: When Start-Ups Get It Right”, Journal of Small Business \& Entrepreneurship, 26 (5): 511-536.

Kaufmann, D., and Schwartz, D. (2008), “Networking: The "Missing Link" in Public R\&D Support Schemes", European Planning Studies, 16 (3): 429-440.

Kollmann, T., Stöckmann, C., Hensellek, S., and Kensbock, J. (2016), European Startup Monitor 2016, Duisburg-Essen: Universität Duisburg-Essen Lehrstuhl für E-Business. Available online at https://duepublico2.unidue.de/servlets/MCRFileNodeServlet/duepublico_derivate_00043444/ESM_2016.pdf (last accessed: April 15, 2019).

Koskela-Huotari, K., and Vargo, S.L. (2016), "Institutions as Resource Context", Journal of Service Theory and Practice, 26 (2): 163-178.

Koskela-Huotari, K., Edvardsson, B., Jonas, J.M., Sörhammar, D., and Witell, L. (2016), "Innovation in Service Ecosystems: Breaking, Making, and Maintaining Institutionalized Rules of Resource Integration", Journal of Business Research, 69 (8): 2964-2971.

Lee, I., and Shin, Y.J. (2018), “Fintech: Ecosystem, Business Models, Investment Decisions, and Challenges", Business Horizons, 61 (1): 35-46. 
Lusch, R.F., and Nambisan, S. (2015), "Service Innovation: A Service-Dominant Logic Perspective", MIS Quarterly, 39 (1): 155-176.

Lusch, R.F., and Vargo, S.L. (2014), The Service-Dominant Logic of Marketing: Dialog, Debate, and Directions, London: Routledge.

Lusch, R.F., Vargo, S.L., and Gustafsson, A. (2016), “Fostering a Trans-Disciplinary Perspectives of Service Ecosystems", Journal of Business Research, 69 (8): 2957-2963.

Maglio, P.P., and Spohrer, J. (2008), "Fundamentals of Service Science”, Journal of the Academy of Marketing Science, 36 (1): 18-20.

Maracine, V., and Scarlat, E. (2009), "Dynamic Knowledge and Healthcare Knowledge Ecosystems", The Electronic Journal of Knowledge Management, 7 (1): 99-110.

McDermott, K., Kurucz, E.C., and Colbert, B.A. (2018), “Social Entrepreneurial Opportunity and Active Stakeholder Participation: Resource Mobilization in Enterprising Conveners of Cross-Sector Social Partnerships", Journal of Cleaner Production, 183: 121-131.

Meynhardt, T., Chandler, J.D., and Strathoff, P. (2016), "Systemic Principles of Value CoCreation: Synergetics of Value and Service Ecosystems", Journal of Business Research, 69 (8): 2981-2989.

Michel, S., Vargo, S.L., and Lusch, R.F. (2008), “Reconfiguration of the Conceptual Landscape: A Tribute to the Service Logic of Richard Normann", Journal of the Academy of Marketing Science, 36 (1): 152-155.

Mokyr, J. (2004), “Accounting for the Industrial Revolution", in R. Floud and P. Johnson (eds), The Cambridge Economic History of Modern Britain, 1700-1860, Cambridge: Cambridge University Press.

Nogueira, T., de Souza, K.F., Fornaro, A., de Fatima Andrade, M., and de Carvalho, L.R.F. (2015), “On-Road Emissions of Carbonyls from Vehicles Powered by Biofuel Blends in Traffic Tunnels in the Metropolitan Area of Sao Paulo, Brazil", Atmospheric Environment, 108: 88-97.

Nonaka, I., and Takeuchi, H. (1995), The Knowledge-Creating Company, Oxford: Oxford University Press.

Nonaka, I., and Toyama, R. (2015), “The Knowledge-Creating Theory Revisited: Knowledge Creation as a Synthesizing Process", in J.S. Edwards (ed.), The Essentials of Knowledge Management, 95-110, London: Palgrave Macmillan.

Orlikowski, W.J. (1992), “The Duality of Technology: Rethinking the Concept of Technology in Organizations", Organization Science, 3 (3): 398-427.

Palumbo, R., Cosimato, S., and Tommasetti, A. (2017), “Dream or Reality? A Recipe for Sustainable and Innovative Health Care Ecosystems", The TQM Journal, 29 (6): 847-862.

Pels, J., Barile, S., Saviano, M., Polese, F., and Carrubbo, L. (2014), “The Contribution of vSa and SDL Perspectives to Strategic Thinking in Emerging Economies: Managing Service Quality", An International Journal, 24 (6): 565-591.

Polese, F., Carrubbo, L., Bruni, R., and Maione, G. (2017), “The Viable System Perspective of Actors in Eco-Systems", The TQM Journal, 29 (6): 783-799.

Prahalad, C. K. and Ramaswamy, V. (2004), "Co-Creation Experiences: The Next Practice in Value Creation", Journal of Interactive Marketing, 18 (3): 5-14. 
Ramaswamy, V., and Gouillart, F.J. (2010), The Power of Co-Creation: Build It with Them to Boost Growth, Productivity, and Profits, London: Simon \& Schuster.

Rasmussen, E., and Wright, M. (2015), “How Can Universities Facilitate Academic Spin-Offs? An Entrepreneurial Competency Perspective", The Journal of Technology Transfer, 40 (5): 782-799.

Reynoso, J. (2009), "Values-Based Service for Sustainable Business-Lessons from IKEA", Journal of Service Management, 20 (4): 473-475.

Ries, E. (2011), The Lean Startup: How Today's Entrepreneurs Use Continuous Innovation to Create Radically Successful Businesses, New York (NY): Crown Books.

Rubin, T.H., Aas, T.H., and Stead, A. (2015), "Knowledge Flow in Technological Business Incubators: Evidence from Australia and Israel", Technovation, 41: 11-24.

Saviano, M., Barile, S., Spohrer, J.C., and Caputo, F. (2017), “A Service Research Contribution to the Global Challenge of Sustainability", Journal of Service Theory and Practice, 27 (5): 951-976.

Saviano, M., Bassano, C., and Calabrese, M. (2010), "A VSA-SS Approach to Healthcare Service Systems the Triple Target of Efficiency, Effectiveness and Sustainability", Service Science, 2: 41-61.

Serbanati, A., Medaglia, C.M., and Ceipidor, U.B. (2011), “Building Blocks of the Internet of Things: State of the Art and Beyond", in C. Turcu (ed.), Deploying RFID-Challenges, Solutions, and Open Issues, 351-366, Rijeka (Croatia): inTech.

Simon, F. (2018), External Knowledge Sourcing from Startups: An Analysis of the Pre-Collaboration Phase, Göttingen (Germany): University of Twente.

Soetanto, D., and van Geenhuizen, M. (2015), “Getting the Right Balance: University Networks' Influence on Spin-Offs' Attraction of Funding for Innovation", Technovation, 36: $26-38$.

Spender, J.C., Corvello, V., Grimaldi, M., and Rippa, P. (2017), “Startups and Open Innovation: A Review of the Literature", European Journal of Innovation Management, 20 (1): 4-30.

Spender, J.C. (1996), “Making Knowledge the Basis of a Dynamic Theory of the Firm”, Strategic Management Journal, 17 (2): 45-62.

Spohrer, J., and Kwan, S.K. (2009), "Service Science, Management, Engineering, and Design (SSMED): An Emerging Discipline-Outline \& References", International Journal of Information Systems in the Service Sector (IJISSS), 1 (3): 1-31.

Spohrer, J., Maglio, P.P., Bailey, J., and Gruhl, D. (2007), “Steps toward a Science of Service Systems", Computer, 40 (1): 71-77.

Storbacka, K., Brodie, R.J., Böhmann, T., Maglio, P.P., and Nenonen, S. (2016), “Actor Engagement as a Microfoundation for Value Co-Creation", Journal of Business Research, 69 (8): 3008-3017.

Strömsten, T., and Waluszewski, A. (2012), "Governance and Resource Interaction in Networks: The Role of Venture Capital in a Biotech Start-Up", Journal of Business Research, 65 (2): 232-244.

Teece, D.J. (2010), “Business Models, Business Strategy and Innovation”, Long Range Planning, 43 (2-3): 172-194. 
Torres, N.N., and Souza, C.R. (2016), “A Literature Review about Technology Startups Ecosystems", in F.A. Siqueira, P. Vilain, C. Cappelli and R. Sidnei Wazlawick (eds), Proceedings of the XII Brazilian Symposium on Information Systems: Information Systems in the Cloud Computing Era (Vol. 1), 385-392, Porto Alegre: Brazilian Computer Society.

Valkokari, K. (2015), “Business, Innovation, and Knowledge Ecosystems: How They Differ and How to Survive and Thrive within Them", Technology Innovation Management Review, 5 (8): 17-24.

van Riel, A.C., Zhang, J.J., McGinnis, L.P., Nejad, M.G., Bujisic, M., and Phillips, P.A. (2019), "A Framework for Sustainable Service System Configuration", Journal of Service Management, 30 (3): 349-368.

Vargo, S.L., Akaka, M.A., and Vaughan, C.M. (2017), “Conceptualizing Value: A ServiceEcosystem View", Journal of Creating Value, 3 (2): 117-124.

Vargo, S.L., and Akaka, M.A. (2012), "Value Cocreation and Service Systems (Re)Formation: A Service Ecosystems View", Service Science, 4 (3): 207-217.

Vargo, S.L., and Lusch, R.F. (2008), "Service-Dominant Logic: Continuing the Evolution", Journal of the Academy of marketing Science, 36 (1): 1-10.

Vargo, S.L., and Lusch, R.F. (2014), "Inversions of Service-Dominant Logic", Marketing Theory, 14 (3): 239-248.

Vargo, S.L., and Lusch, R.F. (2016), "Institutions and Axioms: An Extension and Update of Service-Dominant Logic", Journal of the Academy of marketing Science, 44 (1): 5-23.

Vargo, S.L., and Lusch, R.F. (2017), "Service-Dominant Logic 2025", International Journal of Research in Marketing, 34 (1): 46-67.

Vargo, S.L., Maglio, P.P., and Akaka, M.A. (2008), “On Value and Value Co-Creation: A Service Systems and Service Logic Perspective”, European Management Journal, 26 (3): 145-152.

von Bertalanffy, L. (1969), General System Theory: Foundations, Development, Applications, New York (NY): George Braziller Inc.

Waage, S.A. (2007), “Re-Considering Product Design: A Practical ‘Road-Map’ for Integration of Sustainability Issues", Journal of Cleaner Production, 15 (7): 638-649.

Weiblen, T., and Chesbrough, H.W. (2015), “Engaging with Startups to Enhance Corporate Innovation", California Management Review, 57 (2): 66-90.

Wieland, H., Koskela-Huotari, K., and Vargo, S.L. (2016), “Extending Actor Participation in Value Creation: An Institutional View", Journal of Strategic Marketing, 24 (3-4): 210-226.

Wolfson, A., Tavor, D., Mark, S., Schermann, M., and Krcmar, H. (2011), “Better Place: A Case Study of the Reciprocal Relations between Sustainability and Service", Service Science, 3 (2): 172-181.

Wymer, S.A., and Regan, E.A. (2005), "Factors Influencing E-Commerce Adoption and Use by Small and Medium Businesses", Electronic Markets, 15 (4): 438-453. 